\title{
A REVIEW ON ACOUSTICAL PROPERTIES MEASUREMENT METHODS AND A PROPOSED NOVEL METHOD FOR ACOUSTICAL CHARACTERIZATION OF LAMINATED GLASS USED IN AUTOMOTIVE APPLICATIONS
}

\section{SUDHANSHU KRISHNA SHARMA, AJITANSHU VEDRTNAM \& SAURAV KUMAR}

Department of Mechanical Engineering, Invertis University, Uttar Pradesh, India

\begin{abstract}
Many-a-time, deviation of attention of driver due to excessive noise is among the major factors responsible for accidents, and $54.3 \mathrm{~dB}$ of the sound between 500 to $5000 \mathrm{~Hz}$ is the high noise transmitted to the driver among all the components of the car [1]. Thus, there is a strong requirement for inclusion of acoustical measures for the laminated glass (LG) in IS 2553. The present work includes, a brief review on literature reported on acoustical properties measurement using traditional ASTM E1050-98 (sound absorption testing using impedance tube) and ASTM C423 (sound absorption testing using scale rooms) and acoustical measurements that are reported in literature for biological and other applications. A novel method is also proposed for the acoustical property measurement. The Finite element (FE) simulation for the acoustical property measurement of polyvinyl butyric (PVB) LG (material used for windshield) sample is also performed based on the proposed experimental method.

KEYWORDS: The Finite Element, Polyvinyl Butyric \& Laminated Glass (LG)
\end{abstract}

Received: Jun 17, 2017; Accepted: Jul 05, 2017; Published: Jul 31, 2017; Paper Id.: IJMPERDAUG201728

\section{INTRODUCTION}

LG consists of two plates of glass joined by an elastomeric interlayer to form a unit. In between two layers of glass, viscoelastic polymer is placed and this whole system is together placed using heat and pressure. It improves Mechanical properties of the LG by increasing the area of impact as a result it increases the sound insulation capability. The most commonly used interlayer material for architectural glazing is polyvinyl butyric (PVB). Apart from PVB, other types of interlayer used are ethylene vinyl acetate (EVA) and sentry glass (SG). The interlayer also forms a barrier for the ultraviolet (UV) radiation to penetrate. Apart from the UV barrier, LG is functional as it also dampens noise. All these important functional properties make LG favorable to be used in automotive industry and for construction purposes.

ISO 10534-2, ASTM E1050-98, ASTM E2611-09, ISO 354-2003, JIS A1409, ASTM C423 ISO 140-3, ISO 140-4, SAE J1400 and ASTM E90 are the most commonly adopted standard for acoustical measurements. The present work includes a brief review over literature related to acoustical measurements and later a novel method for acoustical property testing of LG-PVB is suggested. The FE simulation (using COMSOL) is also performed based on the experimental set-up and procedure suggested in the novel method.

\section{LITERATURE REVIEW}

A number of analytical and experimental methods for acoustical properties measurement are cited in the literature, but the acoustical property measurement of LG-PVB is rarely found in the cited literature. The Figure 1 
represents the classification of literature based on acoustical property measurement method utilized. The $26 \%$ of the research papers cited for acoustical measurement utilized room acoustical method and impedance tube method each, whereas $48 \%$ of the literature have reported other measurement methods.

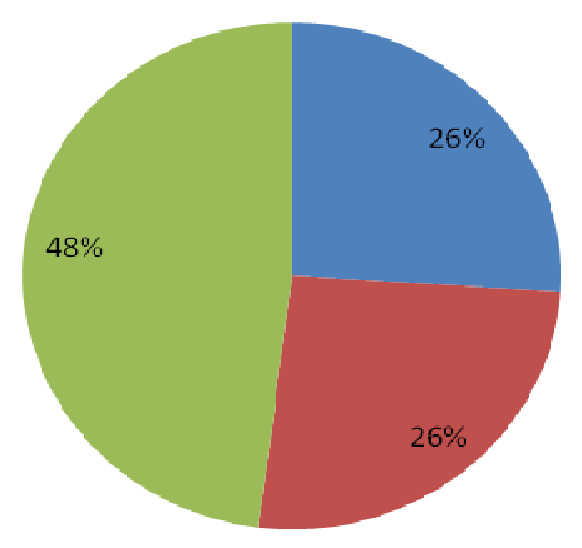

Figure 1: Literature Classification Based on Measurement Methods

LG is studied widely for flexural loading [1-17], impact loading [18-29], blast loading [30-42] and also for photovoltaic and other applications [31-48]. The acoustical performance of LG is comparatively less discussed in cited literature. In the only reported study, Belder et al. estimated an equivalent complex modulus of the LG beams used for sound conduction with loss expectation. In the study, it has been displayed that an equivalent complex modulus of multilayer glass beams can be calculated precisely via broadband flexural vibration test for free boundary conditions. The sound transmission loss of a multilayer plate can be determined using the effective complex bending stiffness [48]. Generally, Many LG manufacturing companies (Guardian glass India Pvt. Ltd, Novo Genio, Mega Luminio, Safelex, DuPont etc.) perform acoustical properties testing for their products. An observation on data published by the LG manufacturing companies reflects the sanitary glass, LG-EVA are superior for sound absorption when compared to LGPVB. Acoustical PVB is also an option that shows excellent acoustical behavior.

\section{Scale Room Methods for Acoustical Measurements}

The study of acoustics revolves around the generation, propagation and reception of mechanical waves and vibrations. The large samples and non-homogeneous object are usually tested following room methods for sound absorption and sound transmission loss. ISO 354-2003, JIS A1409 or ASTM C423 are used for sound absorption measurements and ISO 140-3, ISO 140-4, SAE J1400 and ASTM E90 standards are followed in sound transmission loss measurement using rooms.

Yadav \& Cabrera [49] found that the role of room acoustics, in terms of the auto phonic room response, is complicated as the auto phonic loudness grows in a twisted manner. Gramez \& Boubenider [50] studied the acoustical comfort for a conference room using the inside/ outside ambient noise and interior sound insulation. The acoustic requirements for spaces intended for verbal communication were measured and compared with the reference values suggested by the international standards. Poets et al. [51] determined the temporal and spatial structures of room impulse responses using sound field decomposition by a new approach. Galbrun \& Kitapci [52] evaluated the effect of acoustical condition of a room on the speech intelligibility of four different languages. It was found that speech transmission index was different for different acoustical conditions. Garai et al. [53] summarized the series of papers on the realistic simulation of sound fields in car passenger compartments using a combined FE and Geometrical Acoustics (GA) approach. 

for Acoustical Characterization of Laminated Glass used in Automotive Applications

The simulations are conducted for the whole audible frequency range with the loudspeakers of the car audio system as the sound sources. Eldakdoky [54] discussed the acoustic conditions inside two lecture rooms (Figure 2) in faculty of agriculture, Cairo University, based on field measurements and simulation technique. Ambient sound and reverberation time were measured in the empty rooms. The Experimental results were used for validating the results of CATT software. Reverberation time, STI and C50 were analyzed in comparison with rooms' properties, optimal reverberation time and maximum acceptable sound for learning spaces.

A Rayleigh surface acoustic wave (RSAW) resonator in the company of polyaniline and tungsten oxide nano composite thin film is evaluated as a gas sensor for detecting the presence of NO. This RSAW sensor showed high selectivity with $\mathrm{NO}$ gas to differentiate it from $\mathrm{NO} 2$ and $\mathrm{CO} 2$ gases [55]. Meissner [56] has developed a method that decomposes the real and imaginary part of sound intensity inside enclosures. In addition, a software code was written to simulate the acoustic intensity vector field inside the irregular L shaped. Singh et al. [57] studied performance degradation of a combustion system due to lack of homogeneous thermal and chemical behavior of the gases. An array of microphones and time difference of arrival method was utilized for localization of multiple acoustic sources. Tsilfide et al. [58] monitored the acoustic emission of cutting machining operations in a customary researched area. In addition, the increasing tool wear tests were also performed to find an early run ability warning.

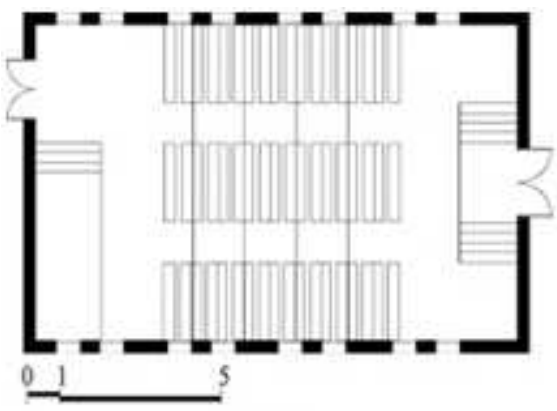

(a) Plan

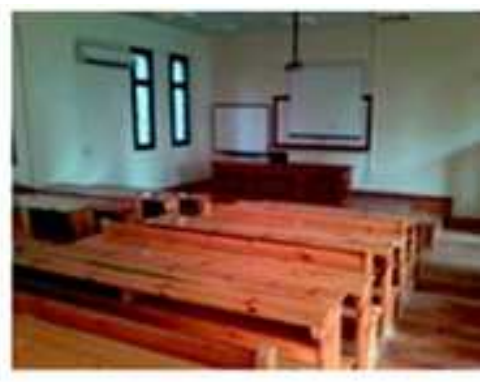

(b) Over view

Figure 2: Layout of Room Tested

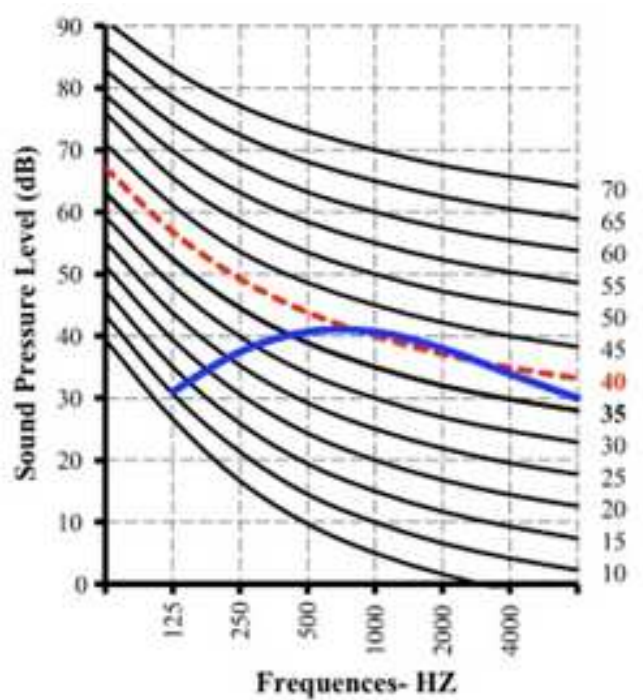

Figure 3: Lave Indicated on NC

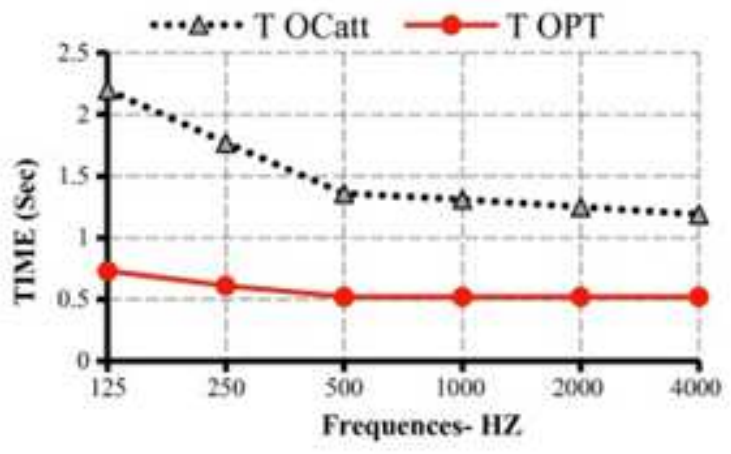

Figure 4: Comparison between T Ocatt and T Opt 
The acoustical evaluation of musical rooms, class rooms, seminar halls, auditoriums and other such settings (Figure 2, 3 and 4) are performed extensively. Choi has tested effect of occupancy on acoustical conditions in university classrooms. The mean sound absorption per occupant was calculated. It was found that the effect of the added absorption of occupants is dependent on the acoustical conditions of the classroom. The more reflective classrooms showed greater changes in acoustical parameter values due to added occupants [59]. Pasquale Bottalico analysed the effects of the acoustical environment and the voice style on time dose and fundamental frequency considering the effect of short-term vocal fatigue. Ten male and ten female subjects were recorded while reading a text in normal and loud styles. The time dose and fundamental frequency was increased in loud style. It was also established that voice acoustical parameters can predict vocal effort [60]. Cerdá et al. determined the acoustical parameters for halls used for the music auditions. It was found that the optimal scores of the acoustical parameters identified in the study, can be used to grade any hall having any shape and use [61].

\section{Acoustical Measurements using Impedance Tube}

A good number of studies are reported, that includes measurement of acoustical properties using impedance tube. An impedance tube (Figure 5) is a mechanical device used to characterize a material on the basis of its capability of transmission, reflection, and absorption of sound waves by determining its transitivity, reflectivity, and absorbability. Niresh et al. [62] designed a low cost impedance tube and compared its performance with the commercially available impedance tube. An error correction mechanism using mathematical modeling and a software code was also suggested. Tang et al. [63] discussed the design of standing wave accelerating tube having an operating frequency of $2998 \mathrm{MHz}$. The design is based on a genetic algorithm and the tube finds application mostly in medical field. Design includes development of a mathematical model for optimizing the arc at the cavity wall to reduce the microwave power loss. The model also optimizes the nose cone to increase the electric field along the axis for accruing high shunt impedance. Cao et al. [64] established that the impedance magnitude is important for the design and function of a Sterling pulse tube cry cooler. In addition, the influence of the impedance magnitude on the viscous and thermal losses was also calculated, that contributes to the overall refrigeration efficiency. Feng [65] standardized two methods for acoustical property measurement using the impedance tube. In addition to two-load or two-source methods, a method having direct and inverted configuration along with the single-microphone method and the other based on the wave field decomposition theory were standardized. Doutres et al. [66] presented an indirect method using three-microphone impedance tube setup used for measurement of the non-acoustic properties of a sound absorbing porous material. Feng et al. [67] suggested improvement in the measurement of complex transmission coefficients in impedance tube by analyzing influence that comes from the transmissionreflection wave. The modified formulas of complex reflection and complex transmission coefficients were also proposed. Ho et al. [68] have measured the complex transmission coefficient having high transmission loss samples using threesensors, two impedance tubes, monotonic wave excitation, and phase sensitive detection. The effectiveness of the method on perforated plate measurements was performed on locally resonant sonic materials. Peter et al. [69] determined if a nasogastric tube predisposes to gastro esophageal reflux in the lower esophagus or stomach for 24 hours. 


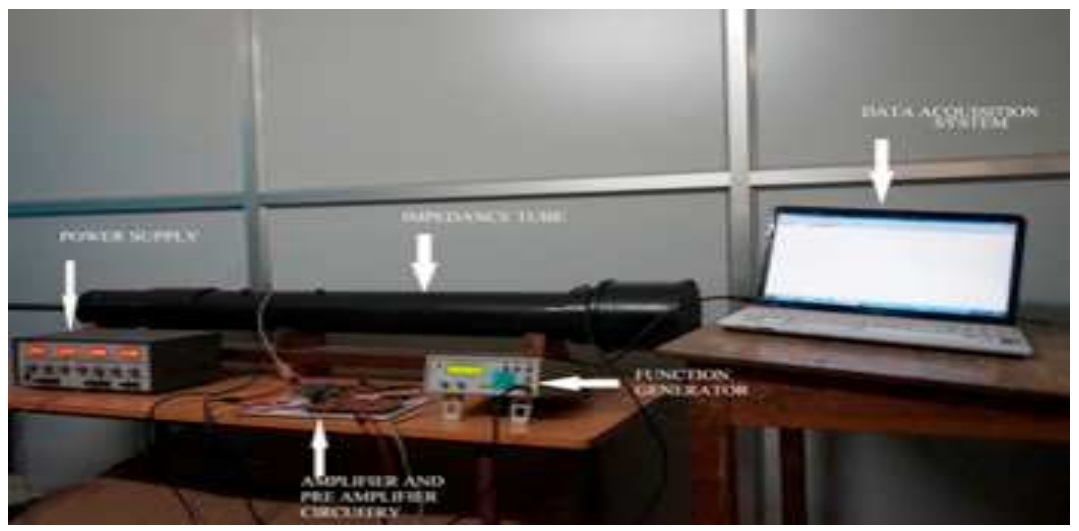

Figure 5: Impedance Tube Setup

\section{Acoustical Measurements for Biological and Other Applications}

Siano et al. optimized the acoustic attenuation properties of a composite sandwich panel (proposed to be used in a high-speed train). The transmission loss was calculated using Nilsson's analytical formulation followed by experimental validation [70]. Xu et al. evaluated the effects of micro-capillary diameter, perforation rate and perforation diameter on the sound absorption performance of the multi-layer plastic micro-capillary film using the standing wave tube method. The multi-layer plastic micro-capillary film was found competitive to perforated panel and porous material for sound absorption applications [71]. Chen et al. constituted a tri-dimensional reticulated porous material using copper fibers. The acoustic performance (sound absorption coefficient and transmission loss) of the TRPM was evaluated considering the different bulk densities and porosity characteristics [72]. Glé et al. evaluated acoustical properties of mixes of hemp particles as a function of density. It was concluded that the basic parameters of the mixes can be directly used to model the acoustical properties and acoustical measurements are useful in characterizing the shape and microstructure of hemp aggregates [73]. Ghofrani et al. have described the acoustical performance of plywood/waste tire rubber (PWTR) composite panels. The specific modulus of elasticity, damping factor, acoustic coefficient, and acoustic converting efficiency of the experimental panels were evaluated by free vibration based on a free-free bar method. It was found that the sound insulation property of PWTR was highly dependent on the variable parameters. The damping factor and acoustical coefficient of PWTR depends on the amount of wood and polymer resin content used in the composite [74].

The relationship between blood pressure and flow waves is described by the input impedance for systemic circulation. Impedance interpretation requires models that utilize the mechanical arterial properties, wave propagation and reflection phenomena. Burattini [75] discussed model structures defined by the parameters that can be estimated by fitting to available pressure and flow measurements. Berengier [76] has performed measurement of the sound absorption coefficient in automobile components, noise barriers, low-noise pavements for controlling traffic noise. Laurics [77] studied free field techniques used for measurement of reflection coefficient of sound absorbing materials. In general, the measurement of the sound pressure is done at few points using a model for the reflection of sound waves on the material. The accuracy of the method depends on the different assumptions made in the model. Few models needs the material to be local reacting or a sound source located far from the surface etc. The errors estimates and ways to increase the frequency interval for reliable results were also explained. Kimura [78] developed a method for measuring oblique incidence absorption coefficient. The noise reduction ability of absorptive panels to be attached on the underside of the upper decks of elevated roads can be accurately estimated using the oblique incidence absorption coefficient. The measurement in-situ 
was the same method as in a semi anechoic room. The field measurements were carried out in four different sites of the underside of the upper decks of elevated roads. In this case, oblique incidence absorption coefficient measured in the field shows good agreement with results from the laboratory. It is also very important to use this technique in in-situ measurement of absorption coefficient for sound absorbing materials attached to structures such as noise barriers and ceilings of double deck viaducts. Using this method, field measurements are carried out at four different sites where absorptive panels are mounted to the underside of upper decks of elevated roads. It is shown that oblique incidence absorption coefficient measured in the field shows good agreement with the result in the laboratory.

$\mathrm{Wu}$ [79] used two-microphone method to measure the absorption coefficient of a non-uniform impedance surface. The sample was a profiled absorber and measurements were made in an anechoic chamber under oblique incidence. The results are compared with predictions. Good agreement has been found in low and middle frequency ranges, where secular reflection dominates the scattered sound field. Significant deviations appear when there is more than one dominating reflected wave; possible solutions to this will be presented. The investigation showed that the two microphone method could be applied to a non-uniform impedance surface to measure the absorption coefficients, provided that the secular reflection dominates the sound field. When secular reflections do not dominate the sound field, the multiple microphone method can be used to solve the strong scattering problems. Garai [80] has conducted the comparative study that includes an inter comparison of laboratory measurement flow. This paper presents the results of an Inter-Laboratory Test (ILT) of airflow resistance measurements on acoustic materials following the ISO 9053 Standard. Each of nine European laboratories received two sheets of melamine foam of different thickness, taken from the same factory batch. The laboratories cut the test samples from the supplied sheets and carried out measurements in repeatability conditions, either on a single sample either on different samples in order to take into account also the influence of the sample cutting and homogeneity of the foam. The main result of this European ILT is the determination of the repeatability and reproducibility standard deviation values typical of these measurements. The data show that most of the laboratories have a good internal repeatability, even if some measurement devices seem to give a better performance than others. On the other hand, the overall reproducibility is only fair, mainly due to systematic deviations inherent in the current laboratory practice; it is suggested that more attention on the calibration of the measurement procedures could lead to better results. Knock [81] discussed application of a free field acoustics impedance apart from standardized methods like standing wave tube and reverberation chamber measurements. Author stated that there can be been several approaches to deduce the absorption coefficient or impedance under approximated free field conditions. Many of the existing procedures assume plane wave propagation and can thus be referred to as geometrical procedures. Other materials and linings of walls have been investigated. The results agree well with literature values and other measurements. For some absorbing structures like plate-like resonators further investigations are needed. Results from strongly diffusing surfaces should be interpreted with care, further investigations will concentrate on this aspect that might be Sound Reflective Test explained the concept of effective impedance as suggested the measurement. Damdinov [82] has studied the dynamical properties of liquids by resonance method with using a piezoquartz. The resonance method for measuring the shear elasticity consists in the following: a piezoquartz crystal performs longitudinal (axial) oscillations at the basic resonance frequency, and its horizontal surface performing tangential oscillations supports a liquid interlayer covered by a solid cover plate. The cover plate with the liquid film is disposed on one end of the piezoquartz crystal. In this case, the liquid interlayer undergoes a shear deformation, and standing shear waves should be induced in it. The parameters of the resonance curve of the piezoquartz crystal vary depending on the interlayer thickness. 
River sand is an important material for the production of concrete, and the water content of sand for mixing with the cement during the manufacture influences the quality of the concrete produced, and the reflectance of ultrasound measured from dry sand surface was rather weaker than that calculated from the general impedance of sand by Naumenko [83]. In order to explain this property, this paper estimates the reflectance by theoretical analysis of reflection from dry sand surface, with the assumptions of plane wave and simple sphere model sand grain. The result shows that the reflectance is independent with the radius of sand grain, if it is small enough than wavelength. The estimation is verified by the measured reflectance of two kinds of sand with different size. Berrier [84] developed a method based on the parametric interaction of two ultrasonic waves for measuring the acoustic nonlinearity parameter. The interaction of a high frequency continuous wave with a low frequency pulse is equivalent to a phase modulation of the high frequency wave. Thus, the nonlinearity parameter is determined by demodulating the continuous-wave phase. This technique circumvents the diffraction effects. Measuring nonlinearity parameters of well-known liquids validates the measurement principle. Absolute measurements require the low frequency transducer calibration with an optical interfero meter. They are given with a 5-\% uncertainty and are in good agreement with those found in literature. By comparing two media, relative measurements are also achievable without any transducer calibration, with a 2-\% precision. This technique is applied for measuring nonlinearity parameters of gelatin gels mimicking biological tissues. Laguerre [85] presented a magneto elastic device for the low-frequency ultrasonic testing of elongated ferromagnetic structures. From experimental observations, the nonlinear behavior of the magneto elastic transduction versus the polarizing field and amplitude of the driving field is illustrated for different material samples. Concurrently, the noncontact magneto elastic device is used to study the guided wave propagation in structures. Finally, defect detection is performed using pulse compression technique. Panneton [86] developed polynomial relations in terms of poison's ratio and shape factor to link the apparent Young's modulus to the true Young's modulus of an isotropic poroelastic disc-shaped sample under quasi-static compression. The method leads to a system of two equations and two unknowns. The unique admissible solutions to the system are the true Young's modulus and Poisson's ratio of the material. Also, using the quasi-static measurements of the compression mechanical impedance, the structural loss factor of the material can be deduced. The method is applied successfully to characterize the three elastic parameters of a poroelastic foam sample. It is shown that the method leads to a unique set of elastic parameters known as the true values of the material and not the apparent values. Ricciardi [87] calculated the sound transmission loss of a perforated screen backed with granular porous media. Theoretical models have been analyzed. Laboratory measurements in coupled reverberant rooms have been carried out from 125 to $5000 \mathrm{~Hz}$ aiming to validating the models. Different model variations have been applied to be more compatible with the analyzed granular material and results have been compared with laboratory measurements. The paper showed that the calculation of acoustic transmission loss of the studied panel well agreed with measurements at frequencies below $2000 \mathrm{~Hz}$. Tran-van [88] has conducted the comparative study that includes most of insulating or absorbing passive systems used in buildings acoustics involve porous materials. In order to predict their fibro-acoustic behavior, it is necessary to determine their intrinsic acoustical parameters. Direct measurement of all parameters is however difficult. To alleviate this difficulty, a recent study has shown that inverse identification methods can be used to find out these parameters. In particular, tortuosity, viscous and thermal lengths can be evaluated from acoustical measurements in a standing wave tube combined with a direct measurement of porosity and resistivity. In this paper, global inverse methods are presented to characterize the acoustical parameters of anisotropic porous materials. The performance of these global inverse methods is discussed in isotropic case. 
The porous rigid materials, by means of an electric or an equivalent fluid analogy, can be analyzed. These are media of rigid structure or lower coupling between the structure and the fluid that is contained in the pores. It is habitual to characterize them by physical parameters, as they are the density of the sample, the porosity, the flow resistivity and acoustic properties, as the characteristic impedance, the complex constant of propagation, the density and the compressibility of an equivalent fluid. The compressibility of the equivalent fluid or their inverse one the bulk modulus, by theoretical, thermodynamic, and microscopic models is usually obtained. The compressibility of the equivalent fluid is calculated and contrasted from acoustic hypothesis and the acoustic measure of the flow impedance for very thin samples were developed by Picard [89]. The uncertainty of the method with respect the variance of the most significative variables that take part of the sound absorption coefficient measurement is discussed by Bonacin [90]. The reproducibility standard deviation was calculated from data obtained in different ILT carried on among Germany and South American laboratories and the results obtained during a repeatability test performed for a mineral wool sample using interrupted noise technique. $\operatorname{Ke}$ [91] established that the ordinarily the absorption curves of MPA for random incidence and that for normal incidence are quite alike, only that the absorption coefficients are more or less reduced and the whole curve is shifted to higher frequencies without any change of shape. Shimoyama [92] shown the relations between the distribution of the sound pressure amplitude radiated by tapping the wood on the surface at the frequency, which gives the space differential of the amplitude maximum and the cave location. It was found that the peak of the sound pressure amplitude appeared close to the inner cave and its level abruptly changed across the surface above the inner cave at higher frequency. Nilsson [93] used a 6 th order wave equation to describe the vibration of the structure. Based on the calculated results and measurements on beams the dynamic properties of the beam were calculated in the entire frequency range. The bending stiffness was also determined at the first few Eigen frequencies, determined using simple FRF measurements.

\section{NOVEL METHOD FOR LG TESTING}

An automobile is usually a closed space that is subjected to noise from outside traffic and inside components as well. A novel method includes construction of a room of standard size of the material, of which, acoustical properties are to be determined. The room is subjected to a plane wave sound from sound source situated at the center of the room and sound pressure level is measured using five sound pressure level indicators, one inside the room and three at boundaries and one outside the room. Later the plane wave sound source is situated outside the room and sound pressure level inside the room is determined. The procedure simulates well the noise in the automobiles. A FE simulation using COMSOL is performed for demonstrating the results obtained for LG-PVB sample. The acoustical properties of LG-PVB having 5 mm each outer glass layers, and $0.38 \mathrm{~mm}$ thick inter-layer are determined. Figure 6 shows the constructed room of LG-PVB. Figure 7 shows the messing and Figure 8 and 9 reflects line graph and sound pressure level for 500,600 and $700 \mathrm{~Hz}$ frequencies. The Figure clearly represents the sound pressure level distribution the room when sound source is situated at the center of the room.

Further, the Figure 10 and 11 represents line graph and sound pressure level distribution in the room of laminated glass when sound source is situated outside the room.

Experiment followed by the FE simulation will give an excellent match for the practical situations faced of the automobiles. 


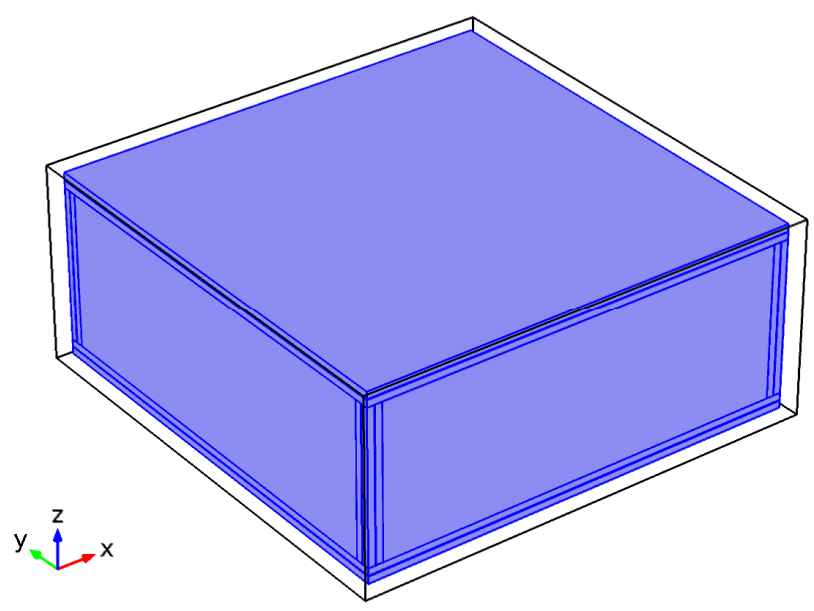

Figure 6: Constructed Room of LG-PVB

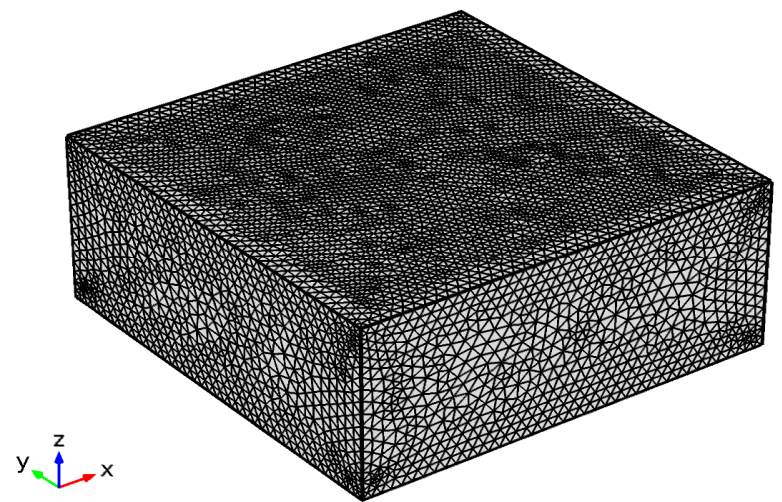

Figure 7: Meshing of the Room of LG

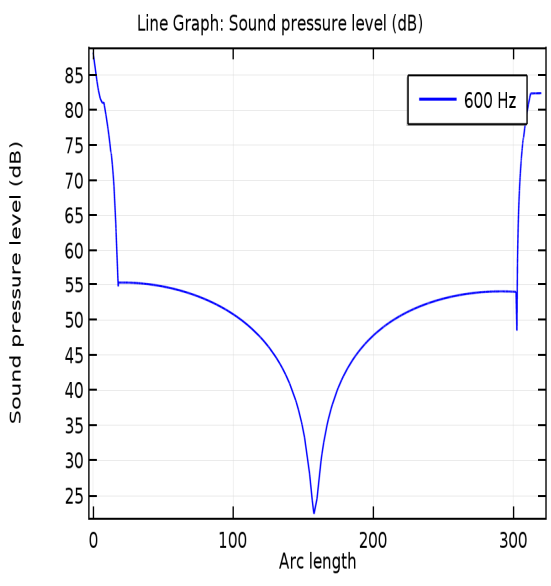

Figure 8: Sound Pressure Db

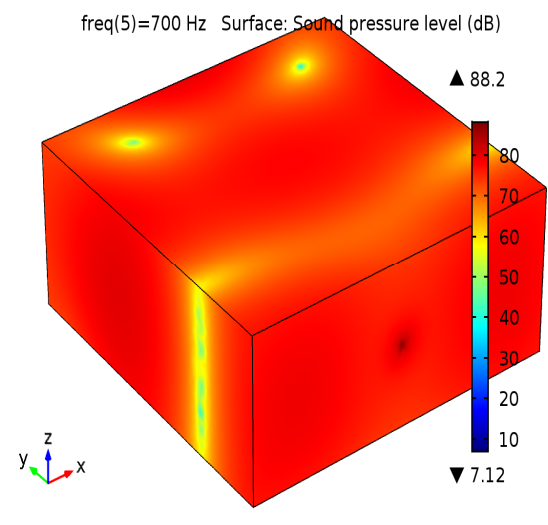

Figure 9: Line Graph

\section{CONCLUSIONS}

This is clearly reflected from the brief review that acoustical characterization of LG is rarely discussed, despite of its growing significance in automotive, structural and other application. Thus, there is a significant requirement of work on 
the LG acoustical characterization. The room acoustics and impedance tube methods are mostly discussed for acoustic characterization of the materials. The novel method suggested is a suitable option for acoustical characterization of the material used in automobiles. It would be better to make a fabricated model of automobile, and simulate same with the finite element model suggested and if that is validated, the finite element model can be built for the automobile for acoustical characterization. This procedure should be added to IS 2553 for making it further sound.

\section{REFERENCES}

1. Jan Belis,Chiara Bedon, Christian Louter, Claudio Amadio, Rudy Van Impe on Experimental and analytical assessment of lateral torsional buckling of LG beams published by Elsevier in Engineering Structures 51 (2013)

2. J.O. Aguilar, O. Gomez-Daza, A. Brito L, m.t.s. nair, p.k. Nair on Optical and mechanical characteristics of clear and solar control LG using zinc sulphide and copper sulphide thin films published by Elsevier in Surface \& Coatings Technology (2005)

3. Mahesh S. Shetty, Lokeswarappa R. Dharani, Jun Wei, Daniel S. Stutts on Failure probability of laminated architectural glazing due to combined loading of wind and debris impact published by Elsevier in Engineering Failure Analysis 36 (2014)

4. Laura Galuppi and Gianni Royer-Carfagni on Laminated beams with viscoelastic interlayer published by International Journal of Solids and Structures 49 (2012)

5. Christian Louter, Jan Belis, Frederic Veer, Jean-Paul Lebet on Durability of SG-laminated reinforced glass beams: Effects of temperature, thermal cycling, humidity and load-duration published by Construction and Building Materials 27 (2012)

6. T. Pyttel, H. Liebertz, J. Cai on Failure criterion for LG under impact loading and its application in finite element simulation published by Elsevier in International Journal of Impact Engineering 38 (2011)

7. J. Belis, J. Depauw, D. Callewaert, D. Delince, R. Van Impe on Failure mechanisms and residual capacity of annealed glass/SGP laminated beams at room temperature published by Elsevier in Engineering Failure Analysis 16 (2009)

8. Jun Xu Yueting Sun, Bohan Liu, Mengyi Zhu, Xuefeng Yao, Yuan Yan,Yibing Li, Xi Chen on Experimental and macroscopic investigation of dynamic crack patterns in PVB LG sheets subject to light-weight impact published by Elsevier in Engineering Failure Analysis 18 (2011)

9. Dong fang Wang, Jialing Yang and Yux in Sun on influence of the middle weak layer on the impact behavior of laminated structures Published by AMSS Press, Wuhan, China Acta Mechanica Solida Sinica, Vol. 26, No. 3, June, 2013

10. Jun Xu, Yibing Li, Bohan Liu, Mengyi Zhu, Dongyun Ge On Experimental study on mechanical behavior of PVB LG under quasi-static and dynamic loadings published by Elsevier in Composites: Part B 42 (2011)

11. M. Timmel, S. Kolling, P. Osterrieder, and P.A. Du Bois on A finite element model for impact simulation with LG published by International Journal of Impact Engineering 34 (2007)

12. M. Seshadri, S.J. Bennison, A. Jagota,and S. Saigal on Mechanical response of cracked laminated plates published by Acta Materialia 50 (2002)

13. F. Collombet, X. Lalbin \& J. L. Lataillade on impact behavior of laminated composites: physical basis for finite element analysis published by Composites Science and Technology 58 (1998) Elsevier Science Ltd

14. Nabil M. Safy El-Din” \& Magdy W. Sabaa on Thermal degradation of poly(vinyl butyral) laminated safety glass published by Polymer Degradation and Stability 41 (1995) Elsevier Science Limited

15. P.A. Hooper, R.A.M. Sukhram, B.R.K. Blackman, J.P. Dear on the blast resistance of LG published by Elsevier in International Journal of Solids and Structures 49 (2012) 
16. Paolo Foraboschi on Analytical model for laminated-glass plate published by Elsevier in Composites: Part B 43 (2012)

17. Salvatore Aiello Giuseppe Campione, Giovanni Minafò, Nunzio Scibilia on Compressive behaviour of laminated structural glass members published by Elsevier in Engineering Structures 33 (2011)

18. J. Zangenberg, S.H.Poulsen, A.Bagger, H.Stang, J.F.Olesen on Embedded adhesive connection for LG plates published by Elsevier in International Journal of Adhesion \& Adhesives 34 (2012)

19. C. Amadio and C. Bedon on Buckling of LG elements in out-of-plane bending published by Elsevier in Engineering Structures $32(2010)$

20. Chiara Bedon, Claudio Amadio on Buckling of flat LG panels under in-plane compression or shear published by Elsevier in Engineering Structures 36 (2012)

21. Luigi Biolzi,Sara Cattaneo, Gianpaolo Rosati on Progressive damage and fracture of LG beams published by Elsevier in Construction and Building Materials 24 (2010)

22. Yao Koutsawa, El Mostafa Daya on Static and free vibration analysis of LG beam on viscoelastic supports published by Elsevier in International Journal of Solids and Structures 44 (2007)

23. Ivelin V Ivanov on Analysis, modeling, and optimization of LGes as plane beam published by Elsevier in International Journal of Solids and Structures 43 (2006)

24. Christian Louter Jan Belis, Frederic Veer, Jean-Paul Lebet on Structural response of SG-laminated reinforced glass beams; experimental investigations on the effects of glass type, reinforcement percentage and beam size published by Elsevier in Engineering Structures 36 (2012)

25. Mehmet Zulfu Asik, Selim Tezcan on A mathematical model for the behavior of LG beams published by Elsevier in Computers and Structures 83 (2005)

26. Laura Galuppi, Gianni Royer-Carfagni on The effective thickness of LG: Inconsistency of the formulation in a proposal of ENstandards published by Elsevier in Composites: Part B 55 (2013)

27. K. DeBelder, R.Pintelon, C.Demol, P.Roose on Estimation of the equivalent complex modulus of LG beams and its application to sound transmission loss prediction published by Elsevier in Mechanical Systems and Signal Processing 24 (2010)

28. Claudio Amadio, Chiara Bedon A buckling verification approach for monolithic and LG elements under combined in-plane compression and bending published by Elsevier in Engineering Structures 52 (2013)

29. H.D. Hidallana-Gamage, D.P. Thambiratnam, N.J. Perera on Failure analysis of LG panels subjected to blast loads published by Elsevier in Engineering Failure Analysis 36 (2014)

30. ZhijunFengn, JinshanLu,XibaoLi on Structure of a macroporous silica film a saninter layer of a LG published by Elsevier in Ceramics International 39 (2013)

31. Laura Galuppi, Giampiero Manara, Gianni Royer Carfagni on Practical expressions for the design of LG published by Elsevier in Composites: Part B 45 (2013)

32. Laura Galuppi, Gianni Royer-Carfagni on The design of LG under time-dependent loading published by Elsevier in International Journal of Mechanical Sciences 68 (2013)

33. Stefan-H. Schulze, Matthias Pander, Konstantin Naumenko, Holm Altenbach on Analysis of LG beams for photovoltaic applications published by Elsevier in International Journal of Solids and Structures 49 (2012)

34. Yuki Shitanoki, Stephen J. Bennison, Yasuhiro Koike on A practical, nondestructive method to determine the shear relaxation 
modulus behavior of polymeric interlayers for LG published by Elsevier in Polymer Testing 37 (2014)

35. Mostafa M. El-Shami, Scott Norville, Yasser E. Ibrahim on Stress analysis of LG with different interlayer materials published by Elsevier in Alexandria Engineering Journal (2012)

36. Laura Galuppi, Gianni F. Royer-Carfagni on Effective thickness of LG beams: New expression via a variational approach published by Elsevier in Engineering Structures 38 (2012)

37. Yong Peng, Jikuang Yang,Caroline Deck, Remy Willinger on Finite element modeling of crash test behavior for windshield LG published by Elsevier in International Journal of Impact Engineering 57 (2013)

38. Martin Larcher, George Solomos, Folco Casadei, Norbert Gebbeken on Experimental and numerical investigations of LG subjected to blast loading published by Elsevier in International Journal of Impact Engineering 39 (2012)

39. Jingjing Chen, Jun Xu, Xuefeng Yao, Xiaoqing Xu, Bohan Liu a, Yibing Lion Different driving mechanisms of in-plane cracking on two brittle layers of LG published by Elsevier in International Journal of Impact Engineering 69 (2014)

40. WeiGao and MengyanZang on The simulation of LG beam impact problem by developing fracture model of spherical DEM published by Elsevier in Engineering Analysis with Boundary Elements 42 (2014)

41. Mehmet Zülfü Asık Ebru Dural, Mehmet Yetmez, Tevfik Uzhan on a mathematical model for the behavior of laminated uniformly curved glass beams published by Elsevier in Composites: Part B 58 (2014)

42. Paolo Foraboschi on Hybrid laminated-glass plate: Design and assessment published by Elsevier in Composite Structures 106 (2013)

43. Zemanova, J. Zeman,M. Sejnoha on Numerical model of elastic LG beams under finite strain published by Elsevier in archives of civil and mechanical engineering (2014)

44. M. López-Aenlle, F. Pelayo, A. Fernández-Canteli, M.A. García Prieto on The effective-thickness concept in laminated-glass elements under static Loading published by Elsevier in Engineering Structures 56 (2013)

45. Wei Xu and Mengyan Zang on Four-point combined DE/FE algorithm for brittle fracture analysis of LG published by Elsevier in International Journal of Solids and Structures 51 (2014)

46. Bedon J. Belis, A. Luible on Assessment of existing analytical models for the lateral torsional buckling analysis of PVB and SG LG beams via viscoelastic simulations and experiments published by Elsevier in Engineering Structures 60 (2014)

47. M. Overend,C. Butchart, H. Lambert, M. Prassas on The mechanical performance of laminated hybrid-glass units published by Elsevier in Composite Structures 110 (2014)

48. Tomas Serafinaviciusa, Jean-Paul Lebeta, Christian Loutera, Tomas Lenkimasc, Artiomas Kuranovas on Long-term LG four point bending test with $P V B, E V A$ and SG interlayers at different temperatures published by Elsevier in Procedia Engineering $57(2013)$

49. Acoustics Testing in Cars of Noise Reducing Laminated Glass using Saflex Q series. Saflex, a unit of Solutia Inc Solutia Inc Jun J. Lu, Ph.D., Thomas Laboda Presented by Michel Van Russelt.

50. Manuj Yadav, Densil Cabrera Speech intelligibility of English, Polish, Arabic and Mandarin under different room acoustic conditions. Applied Acoustics, 2016, Pages 79-91

51. Abdelghani Gramez, Fouad Boubenider, Autophonic Loudness of Singers in Simulated Room Acoustic Environments, 2017, 388.e13-388.e25

52. Corinna S. Peter, Cornelia Wiechers, Bettina Bohnhorst, Jiri Silny, Christian F. Poets. Acoustic comfort evaluation for a 
conference room: A case study. Applied Acoustics, 2017, 118:39-49.

53. Laurent Galbrun, Kivanc Kitapci Combined wave and ray based room acoustic simulations of audio systems in car passenger compartments, Part II: Comparison of simulations and measurements 2014 76, 52-65.

54. Garai. Influence of nasogastric tubes on gastroesophageal reflux in preterm infants: A multiple intraluminal impedance study. 141: 2002, 277-279.

55. Marc Aretz, Michael Vorländer Optimizing acoustic conditions for two lecture rooms in Faculty of Agriculture, Cairo University Ain Shams Engineering Journal, In Press, 12 September 2016.

56. Soha Eldakdoky Sensors and Actuators B: Chemical, Volume 156, Issue 2, August 2011, Pages 668-672.

57. Shih-Han Wang, Shih-Hao Kuo, Chi-Yen Shen Optimizing acoustic conditions for two lecture rooms in Faculty of Agriculture, Cairo University12 September 2016

58. Analytical and numerical study of acoustic intensity field in irregularly shaped room Applied Energy109:2013,171-181.

59. A.V. Singh, M. Yu, A.K. Gupta, K.M. Bryden nal Research Article Applied Acoustics, 2013: 661-668

60. Pasquale Bottalico. Speech Adjustments for Room Acoustics and Their Effects on Vocal Journal of Voice, Volume 31, Issue 3, May 2017, Pages 392.e1-392.e12.

61. S. Cerdá, A. Giménez, J. Romero, R. Cibrián, J.L. Miralles. Room acoustical parameters: A factor analysis approach. Applied Acoustics, Volume 70, Issue 1, January 2009, Pages 97-109.

62. Young-Ji Choi. Effect of occupancy on acoustical conditions in university classrooms. Applied Acoustics, Volume 114, 15 December 2016, Pages 36-43.

63. Mirostaw MeissnerAutomatic speech recognition performance inifferent room acoustic environments with and without dereverberation preprocessing 2013: 380-395

64. Alexandros Tsilfidis, Iosif Mporas, John Mourjopoulos, Nikos Fakotakis Investigation and correction of error in impedance tube using intelligent techniques 14/ 6 December 2016: 405-414

65. J. Niresh, S. Neelakrishnan, S. Subha Rani Journal of Applied Research and Optimal design of a standing-wave accelerating tube with a high shunt impedance based on a genetic algorithmTechnology 14/2016: 405-

66. Zhenxing Tang, Yuanji Pei, Jian PangImpedance magnitude optimization of the regenerator in Stirling pulse tube cryocoolers working at liquid-helium temperatures58, December 2013, Pages 38-44

67. Q. Cao, L.M. Qiu, X.Q. Zhi, L. Han, Z.H. Gan, X.B. Zhang, X.J. Zhang, D.M. SunModified impedance tube measurements and energy dissipation inside absorptive materials74, 2013: 1480-1485

68. Leping Feng Downstream from the Heart Left Ventricle: Aortic Impedance Interpretation by Lumped and Tube-Load Models2014, Pages 503-525

69. Roberto Burattini Modeling Methodology for Physiology and Medicine (Second Edition) Normal incidence sound transmission loss in impedance tube Measurement and prediction methods using perforated plates Applied Acoustics, 68: 2007/ 1485-1493

70. Naoki Kino, Takayasu Ueno Investigation of sample size effects in impedance tube measurements Measurements of sound transmission through panels of locally resonant materials between impedance tubes Original Research Article Applied Acoustics 66: 7/2005/751-765

71. Kin Ming Ho, Z. Yang, X.X. Zhang, Ping Shang Influence of nano gastric tubes on gastro esophageal reflux in preterm infants: 
A multiple intraluminal impedance study Original Research Article The Journal of Pediatrics, 141: 2002/277-279

72. Mohammad Ghofrani, AlirezaAshori, Mohammad HadiRezvani, Chen . Acoustical properties of plywood/waste tire rubber composite panels. Measurement 94: 2016, Pages 382-387.

73. Laura Galuppi, Gianni Royer-Carfagni on Enhanced Effective Thickness of multi-layered LG published by Elsevier in Composites: Part B 64 (2014)

74. Richard A. Behr, M. ASCE, Joseph E. Minor, Ghofrani, and Magnus P. Linden on load duration and interlayer thickness effects on LG published by Journal of Structural Engineering, Vol. 112, No. 6, June, 1986

75. Paolo Foraboschi on Behavior and Failure Strength of LG Beams published by journal of engineering mechanics ${ }^{\circ}$ asce december 2007

76. C. V. Girija Vallabhan, Y. C. Das, Members, ASCE, and Manjunatha Ramasamudra on properties of pvb interlayer used in LG published by Journal of Materials in Civil Engineering, Vol. 4, No. 1,February, 1992. ASCE

77. F. W. Flockerl and L. R. Dharan on Low velocity impact resistance of laminated architectural glass published by Elsevier in J. Archit. Eng. 1998

78. Richard A. Behr,l Member, ASCE and Paul A. Kreme on performance of LG units under simulated windborne debris impacts published by journal of architectural engineering / September 1996

79. Lokeswarappa R. Dharani; Fangsheng Ji Richard A. Behr, F.ASCE3; Joseph E. Minor, F.ASCE; and Paul A. Kremer on Breakage Prediction of LG Using the "Sacrificial Ply" Design Concept published by journal of architectural engineering asce / December 2004

80. [79]M. L. Aenlle and F. Wu. Frequency Response of LG Elements: Analytical Modeling and Effective Thickness. Applied Mechanics Reviews VC 2013 by ASME MARCH 2013, Vol. 65

81. Laura Andreozzi, Silvia Briccoli Bati, Mario Fagone, Giovanna Ranocchiai, Fabio Garai Dynamic torsion tests to characterize the thermo-viscoelastic properties of polymeric interlayers for LG published by Elsevier in Construction and Building Materials 65 (2014)

82. Chiara Bedon and Claudio Amadio on Flexural-torsional buckling: Experimental analysis of LG elements published by Elsevier in Engineering Structures 73 (2014)

83. H.D. Hidallana-Gamage, D.P. Thambiratnam, Damdinov on Numerical modeling and analysis of the blast performance of LG panels and the influence of material parameters. Engineering Failure Analysis 45 (2014)

84. Konstantin Naumenko and Victor A. Eremeyev on A layer-wise theory for LG and photovoltaic panels.Composite Structures $112(2014)$

85. Bong Hwan Kim, Tran-van and Berrier on Low Velocity Impact Behaviors of a LG Smart Science Vol. 2, No. 4 (2014)

86. Claude Lefèvre, Philippe Journal picard of Statistical Planning and Inference, Volume 141, Issue 4, April (2011).

87. Alain Clément, Bernard Panneton Richard Bastien, Pauline Fernandez Journal of Food Engineering, Volume 204, (July 2017).

88. Guozhen Xu, Jean-François Deconinck, Qinglai Feng, François Baudin, Pierre Pellenard, Jun Shen, Ludovic Bruneau Palaeogeography, Palaeoclimatology, Palaeoecology, Volume 474, (15 May 2017).

89. Earth and Planetary Science Letters, Volume 458, 15 January 2017, Pages 429-441 Brigitte Knapmeyer-Endrun, Frank Krüger, Wolfram H. Geissler, the PASSEQ Working Group. 

for Acoustical Characterization of Laminated Glass used in Automotive Applications

90. cas picard. method for fractional equation Applied Mathematics and Computation, Volume 307, 15 August 2017, Pages 102112.

91. Rodrigo Bonacin, Olga Fernanda Nabuco, Ivo Pierozzi Junior Future Generation Computer Systems, Volume 54, January( 2016).

92. Tuan Phong Ly, Honggen Ke. Tourism Management Perspectives, Volume 17, January (2016).

93. Shimoyama. Method and apparatus for evaluation of softeninig meltingof coal shimoyama Fuel and Energy Abstracts, Volume 40, Issue 3, May 1999, Page 235.

94. Angular momentum projection for a nilsson mean-field puls pairing model Nilsson, Yin Wang, Feng Pan, Kristina D. Launey, Yan-An Luo, J.P. Draayer Nuclear Physics A, Volume 950, June 2016, Pages 1-28. 
